cells of the islets of Langerhans in the pancreas, causing insulin deficiency. Celiac disease (CD) has been seen in 3 to $8 \%$ of T1DM patients. Celiac disease is characterized by impaired immunological response to ingested gluten. Gluten consumption might be a shared causative factor for the development of T1DM and CD. Celiac crisis is a life-threatening condition in which $\mathrm{CD}$ causes acute dramatic metabolic dysregulation.

Methods A 52-year old lady with a 10-year history of type 1 diabetes mellitus presented with 2-months history of diarrhea associated with loss of appetite, nausea, pain abdomen, and weight loss of $13 \mathrm{~kg}$.

Initial laboratory findings revealed hyperglycemia, metabolic acidosis with hyperchloremia, hypokalemia, hypocalcemia, and hypoalbuminemia. She also had iron and folate deficiency. Haemoglobin level was $9.4 \mathrm{~g} / \mathrm{dl}$. HIV status and viral hepatitis serology were negative, and stool examination did not suggest an infectious etiology.

For evaluation of diarrhea, serological blood test for celiac disease was done; antiendomysium antibodies of the immunoglobulin A (anti EA IgA) was $158.7 \mathrm{U} / \mathrm{ml}$ (normal: 0-20 U/ $\mathrm{ml}$ ), tissue transglutaminases of immunoglobulin A (tTGA IgA) was $>200 \mathrm{U} / \mathrm{ml}$ (normal: 0-20 U/ml). Histological findings of duodenal biopsy post endoscopy were consistent with celiac disease grade 3 according to the Marshal classification. After the introduction of the gluten-free diet, she gained weight, her metabolic abnormalities resolved with better glycemic control.

Results After excluding other reasons of acute diarrhea and based on the patient's findings including metabolic acidosis, hypoproteinemia, hypocalcemia, hypokalemia and weight loss of $13 \mathrm{~kg}$, our patient was diagnosed with celiac crisis. Advising a gluten-free diet results in prompt and dramatic improvement in the patient's symptoms.

Conclusions In the literature, celiac crisis in adults have rarely been notified, and for this reason, celiac disease rarely is considered in adults presenting with acute severe diarrheal illness, even when infectious etiologies have been excluded. A type 1 diabetic patient who presents with severe unexplained diarrhea and malabsorption should be tested for celiac disease.

\section{IDDF2019-ABS-0014 GASTROINTESTINAL SYMPTOMS AMONG HOSPITALIZED CHILDREN ADMITTED WITH H1N1 INFECTION: A REPORT FROM A TERTIARY HOSPITAL IN NORTH INDIA}

Deepak Kumar*, Garima Gupta, Urmila Jhamb. MD , Pediatrics, India

\subsection{6/gutjnl-2019-IDDFabstracts.114}

Background H1N1 influenza A virus has caused massive morbidity and mortality worldwide and still is a threat. Clinical profile from adult patients had emerged from 2009 and 2015 outbreak, very little data is available on pediatric patients especially those requiring hospitalization. Due to adverse biological nature of the virus which involves structural and antigenic modifications, the clinical presentation also needed to be updated. There are several reports available among all hospitalized patients infected with H1N1 in 2009 outbreak from India and other affected countries. However, pediatrics data was scarce.

Methods A study was conducted on the children below 12 years who were H1N1 confirmed cases and required hospitalization. Confirmation was made using throat swab PCR identification of the virus. A total of 22 patients were included during the course of the outbreak.

Results In this study, we have discussed the clinical profile of 22 confirmed patients (table. 1). We have observed that apart from the fever and respiratory symptoms (cough, coryza, RD) patients also presented with GIT symptoms (vomiting, diarrhea $\&$ pain abdomen). There are few other studies had observed GIT symptoms in confirmed swine flu patients. Apart from the presenting symptoms, we have observed that these symptoms progress rapidly over a few days, the patient may present with respiratory distress of varying severity. However, it is seen that the presence of hypoxia is significant. We have seen that patients in whom antiviral therapy was initiated initially ( $<72$ hours), all of them had improved.

\begin{tabular}{|c|c|c|c|}
\hline S. No. & Characteristics & Number & Percentage \\
\hline \multirow[t]{9}{*}{ 1. Symptoms } & Cough/Coryza & 22 & $100 \%$ \\
\hline & Fever & 22 & $100 \%$ \\
\hline & $\mathrm{RD}$ & 20 & $90 \%$ \\
\hline & Mild & 6 & $50 \%$ \\
\hline & Mod & 3 & $22.7 \%$ \\
\hline & Severe & 11 & $27 \%$ \\
\hline & Vomiting & 5 & $18 \%$ \\
\hline & Diarrhea & 6 & \\
\hline & Pain Abdomen & 4 & \\
\hline \multirow[t]{4}{*}{ 2. Spo2 } & $>94$ & 8 & \\
\hline & $94-90$ & 4 & \\
\hline & $90-80$ & 7 & \\
\hline & $<80$ & 3 & \\
\hline \multirow[t]{3}{*}{ 3. Complications } & ARDS & 3 & $13.6 \%$ \\
\hline & Pulmonary Bleed & 5 & $22.7 \%$ \\
\hline & Shock & 5 & $22.7 \%$ \\
\hline
\end{tabular}

Conclusions Early identification of illness, initiation of therapy $\&$ support can modify the disease outcome. Presence of risk factors and pre-illness morbidity in patients acquired H1N1 infection needs strict monitoring and aggressive treatment. Patients presenting with GIT symptoms especially during the outbreak period should not be ignored for H1N1 infectivity.

\section{IDDF2019-ABS-0015 EFFECT OF GLUTEN-FREE DIET ON NUTRITION OF NEWLY DIAGNOSED CHILDREN WITH CELIAC DISEASE}

Madhavi Bharadwaj*, Anand Prakash Dubey, Seema Kapoor. Department of Pediatrics, Maulana Azad Medical College, India

\subsection{6/gutjnl-2019-IDDFabstracts.115}

Background Celiac disease(CD) is a common, often neglected health care problem with avoidable mortality and morbidity in the Indian population with a prevalence of 0.9 to $1 \%$. We studied the effect of gluten-free $\operatorname{diet}(\mathrm{GFD})$ on nutrition of newly diagnosed children in our population where multiple causes of malabsorption coexist. We also aimed at formulating an optimum follow up schedule according to the expected change in nutritional parameters and avoid unnecessary hospital visits and blood investigations

Methods 51 children with no known chronic disorder, between 1 - 10 years, diagnosed with CD were enrolled. 